\title{
Refine design parameters for permanent magnet shape modification of the direct-drive generator
}

\author{
Noor Syazana Abd Ghani, Taib Ibrahim, Nursyarizal Mohd Nor \\ Department of Electrical and Electronic Engineering, Universiti Teknologi PETRONAS, Perak, Malaysia
}

\begin{abstract}
Article Info
Article history:

Received Jun 30, 2021

Revised Jan 24, 2022

Accepted Jan 31, 2022

\section{Keywords:}

Linear generator

Permanent magnet

Refine parameter design

Wave energy converter

Wave power

ABSTRACT

The high cost associated with operation has promoted the progress of wave energy conversion and has higher power output and larger size. However, many countries are bordered by the sea, and the possible area for using wave energy is very small which can generate peak power generation systems with a power output of less than $100 \mathrm{~W}$. The purpose of this article is to introduce the refined parameters of new design of the permanent magnet shape of with tubular longitudinal direct-drive generator. Three designs proposed, which different shapes of permanent magnets with same topology. The parameter optimization process was analysed using finite element analysis to determine the best main parameters of the design, namely the length of the stator length to translation ratio $\left(L_{s} / L_{r}\right)$, pitch ratio $\left(\tau_{m r} / \tau_{p}\right)$, and split ratio $\left(R_{m} / R_{e}\right)$. To evaluate design performance, electrical losses from the proposed design were also evaluated. The optimization results show these designs generator can produce $100 \mathrm{~W}$ of peak level output power with higher efficiency at rated current and optimal load.
\end{abstract}

This is an open access article under the CC BY-SA license.

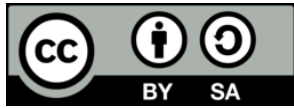

\section{Corresponding Author:}

Taib Ibrahim

Department of Electrical and Electronic Engineering, Universiti Teknologi PETRONAS

Seri Iskandar, 32610, Perak, Malaysia

Email: taibib@utp.edu.my

\section{INTRODUCTION}

Wave energy has attracted tremendous attention due to its high energy density all around the world [1], [2], and it is predictability that is better than wind energy [3]. Ocean wave energy has high availability across the world [4]. Malaysia has recorded a lower wave energy availability of $6 \mathrm{~kW} / \mathrm{m} \mathrm{[3]-[6].} \mathrm{However,} \mathrm{the}$ low-density wave energy along the coast of Malaysia can be used by peak power generation systems with an output power of less than $5 \mathrm{~kW}$ [7]-[9] to facilitate the low power application. The direct-drive linear conversion can be used in wave-activated body (WAB) technology for wave energy conversion purposes [10] [11]. Therefore, the equipment based on this technical principle, especially point absorption equipment [12], may be developed as a portable peak power generation system [13]. The buoy rises and falls according to the movement of the waves to drive the permanent magnet linear generator (PMLG) [14], [15]. No field windings in the moving parts of the machine, resulting in adequate low power induction to generate peak level power [16], [17] and the use of permanent magnet has been considered a good choice in moving part where high performance drives are required to generate high performance of pico-scale output power [18]. Thus, this paper discusses the refined parameters of new design of the permanent magnet shape of with tubular longitudinal direct-drive generator. The refine design parameter involved with length of stator over the length of the rotor $\left(L_{s} / L_{r}\right)$, pitch ratio $\left(\tau_{m r} / \tau_{p}\right)$, and split ratio $\left(R_{m} / R_{e}\right)$ are discussed. 


\section{GENERATOR PROPOSED DESIGNS}

The linear generator is proposed using wave energy to construct a pico-scale linear generator with $100 \mathrm{~W}$ output power by developing multiple forms of permanent magnets. The development of PMLG in this paper is proposed to be in tubular configuration with a short stator for the initial conceptual design. Then, the parameter will be refined by simulate in reverse engineering concept to analyze the efficiency of the performance.

\subsection{Initial dimension of generator design}

As the conventional design of the quasi-Halbach magnetized machine with rectangular, and trapezoid magnets has been reported in [19], three design generator machine, quasi-Halbach magnetized machine with LT-shape, LT-separated and T shape magnets are analysed for the direct drive wave energy converters (WEC) system. Figure 1 shows the schematics and design characteristics in the 2 dimensional (2D) and cross-sectional geometry. Figure 1 (a) shows the T-shape which the axial and radial magnet oppose to the surface of stator. This design will have the higher attraction of magnetic flux. While Figure 1 (b) shows the LT-shape which axial and radial combine in order to analyse the magnetic field that will affect the performance of electromagnetism [20]. Figure 1 (c) which is LT-separated magnet. The axial magnet array does not expose to the air gap which led to the lower magnetic flux. Surface area and volume of the radial array are high which may produce more flux to the armature. The proposed designs machine reported have the same topologies with different magnets shape. The relevant variable and symbols are defined as in Table 1.

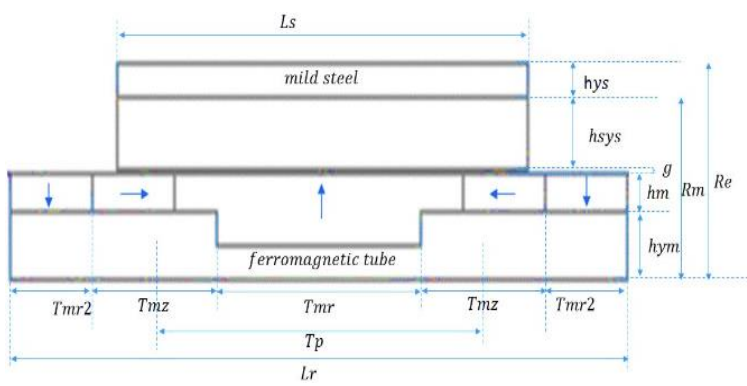

(a)

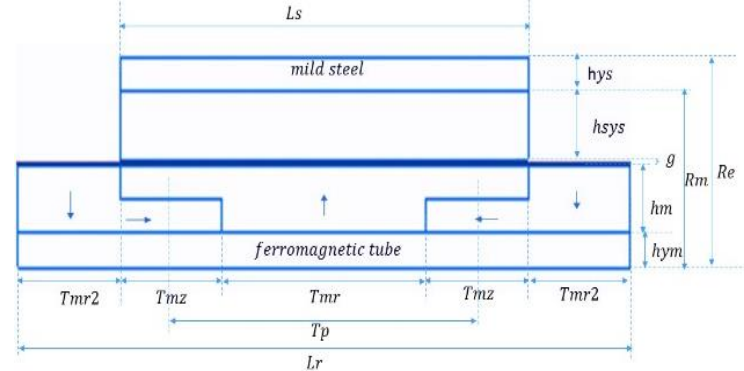

(b)

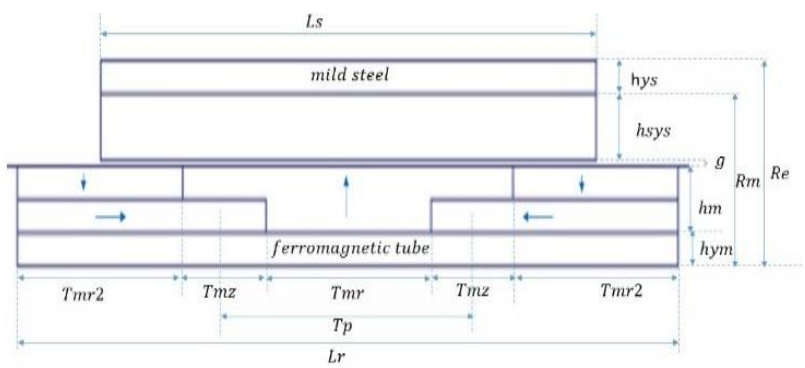

(c)

Figure 1. 2D initial designs (a) T-shape design, (b) LT-shape design and (c) LT-separated design

Table 1. Initial dimension of designs

\begin{tabular}{|c|c|c|}
\hline & Description & Value (mm) \\
\hline$L_{s}$ & Length of stator & 90 \\
\hline$h_{y s}$ & Height of mild steel & 5 \\
\hline$h_{s y s}$ & Height of winding coil & 10 \\
\hline$g$ & Air gap & 1 \\
\hline$R_{m}$ & Outer radius of magnet & 25 \\
\hline$R_{e}$ & Outer radius of the stator core & 41 \\
\hline$h_{m}$ & The radial thickness of magnets & 50 \\
\hline$h_{y m}$ & The radial thickness of the supporting tube & 5 \\
\hline$\tau_{m r}$ & Axial length of the radical magnetized magnet at the center & 50 \\
\hline$\tau_{m z}$ & Axial length of axially magnetized magnets & 10 \\
\hline$\tau_{p}$ & Pole pitch & 70 \\
\hline$L_{r}$ & Length of translator & 150 \\
\hline
\end{tabular}


The stator is selected to be a slotless stator, which is more preferred in wave energy conversion owing to their electromagnetic characteristic which obtains minimum cogging force and can resist the translating part to move smoothly [19], [21], [22]. The thickness of stator core $h_{y s}$ is fixed to the $5 \mathrm{~mm}$ as it will hold the stator winding in place and helps the winding to transmit the flux. While increase the thickness of the stator winding $h_{s y s}$ is significant as influence on the performance of design machine. The length of stator $L_{s}$ is usually shorter than length of translator $L_{r}$. The common length of the stator and translator affect the power rating of the performance design. Thus, decrease the $L_{s}$ and increase the $L_{r}$ is more convenient to improve the power generated. As $h_{m}$ is increased, the performance normally improves. Increased volume of rare-earth magnet material, on the other hand, will raise the cost and result in a heavier armature, which is normally a disadvantage for a reciprocating moving-magnet machine [22]. Thus, the thickness of the magnet $h_{m}$ considers $50 \mathrm{~mm}$ to produce higher flux density and thrust force capability. However, the $h_{m}$ are supported $h_{y m}$ by the ferromagnetic material as external magnetic field so that the flux will be more aligned with the direction of the field. The airgap length, $g$, is fixed to $1 \mathrm{~mm}$ due to minimum assembly tolerance. The influence of the axial length of the radial magnetized magnet $\tau_{m r}$ and axial length of axial magnetized magnet, $\tau_{m z}$ also analyzed which have significant influence on the design machine performance and require to be improve the dimension ratios $\tau_{m r} / \tau_{p}$. The radial and axial magnetization of the magnet plays a predominant role in the design of magnetic bearing for optimum design. The radial width usually has the longer width than the axial width to produce a high attraction force. The designs dimension was improved using the influence parameter ratio calculations to confirm the significant effects on the linear generator efficiency and performance to have the optimum parameters.

\subsection{Refine design parameter}

The determination of optimal parameters from the proposed PMLG designs was carried out by varying the leading design parameters to quantify the influences on the performances of the design. The ratio of $L_{s} / L_{r}$ provided the essential part in determining the optimal amount of magnetic flux that interacts with the coils inside the armature. $L_{s} / L_{r}$ influenced the magnetic flux that passed through the coil and was correlated with the voltage induced by the coil. The leading parameter of $\tau_{m r} / \tau_{p}$ ratio reflected the combined effects of radially and axially magnetized magnets to achieve a maximum fundamental radial flux density in the air gap [23]-[26]. The dimension sizes of all the permanent magnet designs were different due to the different shapes of the permanent magnets used during the designing process. The variation of pitch ratio was created by varying the length of $\tau_{m r}$, but the length of the $\tau_{p}$ was kept constant. The initial $\tau_{m r} / \tau_{p}$ depended on the best variation ratio performance from the $L_{s} / L_{r}$. Meanwhile, refining of $R_{m} / R_{e}$ ratio dimension represents the optimal balance between electrical and magnetic loading to achieve maximum motor efficiency. The motor efficiency was optimized in this study in terms of both dimensional ratios. This leading parameter produced the highest force density. This design refinement was conducted using the finite element analysis (FEA) to acquire the optimal leading parameters that produce maximum efficiency. The efficiency can be calculated is being as.

$$
\eta=\frac{P_{\text {out }}}{P_{\text {out }}+P_{c u}+P_{f e}} \times 100 \%
$$

The $P_{\text {out }}, P_{c u}$, and $P_{f e}$ symbols refer to the output power, copper loss, and iron loss. $P_{c u}$ can be calculated as:

$$
P_{c u}=I^{2} R
$$

where the $I$ symbol is referring to the current, and the $R$ symbol is referring to the resistance. $P_{f e}$ is taking place magnetically in the iron parts of the permanent magnet due to time-varying flux density. $P_{f e}$ can be further divided into eddy currents, hysteresis, and excess losses. The total $P_{f e}$ can be determined is being as;

$$
P_{f e}=\Sigma\left(P_{h i}+P_{c i}+P_{e i}\right.
$$

where the $P h i, P c$, and $P e i$ symbols refer to the hysteresis, excess, and eddy current losses, respectively. The magnitude of these losses strongly depended on the size of the conductive iron.

\section{OPEN-CIRCUIT SIMULATION OF INITIAL DESIGN}

The open-circuit simulation of the initial design was performed using finite element analysis. The back electromotive force (EMF) was produced when the permanent magnet-based rotor moved at the rated velocity within the static armature limits. The back-EMF is determined by taking the derivative of flux linkage 
which is found by stepping the stator through the translator at a constant velocity and measuring the flux linkage at each step. Thus, the results back-EMF waveforms with a sine wave, as shown in Figure 2. The back-EMF waveform of the proposed designs displays distorted sine waveforms. However, the back-EMF values for all the proposed designs exceeded the rated designs $100 \mathrm{~V}$ for the generation of open circuit and pico-scale generator output power. The designs were further tested for refining design parameters analysis. The optimal leading parameters involved the length of stator over the length of translator ratio $\left(L_{s} / L_{r}\right)$, pitch ratio $\left(\tau_{m r} / \tau_{p}\right)$, and split ratio $\left(R_{m} / R_{e}\right)$.

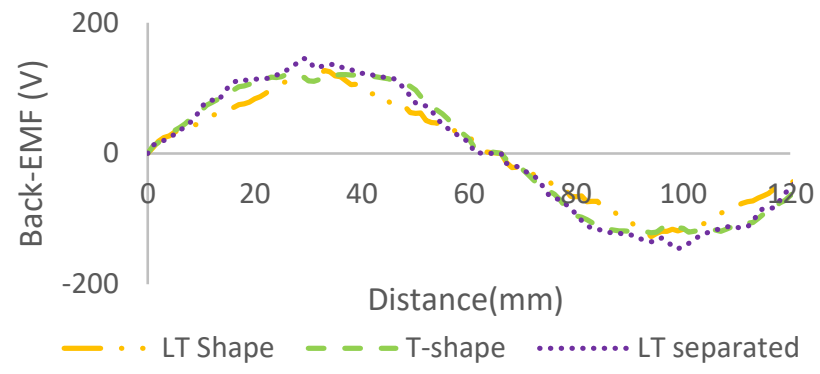

Figure 2. Back EMF

\subsection{Influence of length of stator over length of rotor, $L_{s} / L_{r}$}

Length of stator over length of rotor, $L_{s} / L_{r}$, ratios provide a study bond between the dimension of the stator and translator geometry and the motion of the translator. The power losses and efficiency of the proposed designs were acquired by injecting varying currents at the input (i.e., operates as a motor) to achieve a constant $100 \mathrm{~W}$ power output by neglecting the power losses Figure 3 (a) shows the achieved 100W output power by varying the currents between $0.6 \mathrm{~A}$ to $1.4 \mathrm{~A}$ as in Figure 3 (b). The input current for the designs was increaseed when the ratio of the stator length over the rotor length increased to $100 \mathrm{~W}$.

The average air-gap flux density, average back-EMF, losses, and efficiency of $L s / L r$ variations are tabulated in Table 2. The stator length influenced and affected the electromagnetic field's strengths. The proposed LT shape and T-shape designed were showing higher air gap flux density at the ratio of 1.2 and 1.4, respectively, while the proposed LT-separated shape showed higher air gap flux density at the of ratio 0.6. The findings observed that when the magnet end pointed to the end of the stator exhibited magnetic force and was probably caused by the shape that affects the magnetic energy distribute in the space occupied. However, the influence dimension $L_{S} / L_{r}$ variation effects on the copper loss. The increased copper loss was increasing the ratio changes, which increases the length of the stator. The proposed LT shape, T-shape, and LT-separated designs were reported to have a lesser copper loss at the ratio of 0.4 , caused by the considerable reduction of the stator length and consequently resulted from the decrease in copper losses. Meanwhile, the proposed slotless stator configuration for the detent force reduction in the designs found that the effects to the smaller winding inductance. Thus, minimal magnetic flux leakage was produced. The LT shape, T shape, and LTseparated shape designs presented the best efficiency values at the $L s / L r$ ratio of 0.4 , with the recorded efficiency values of $67.77 \%, 75.06 \%$, and $76.39 \%$, respectively. The designs that showed the optimal $L s / L r$ ratio variation was used to optimize the $\tau_{m r} / \tau_{p}$ leading parameter.

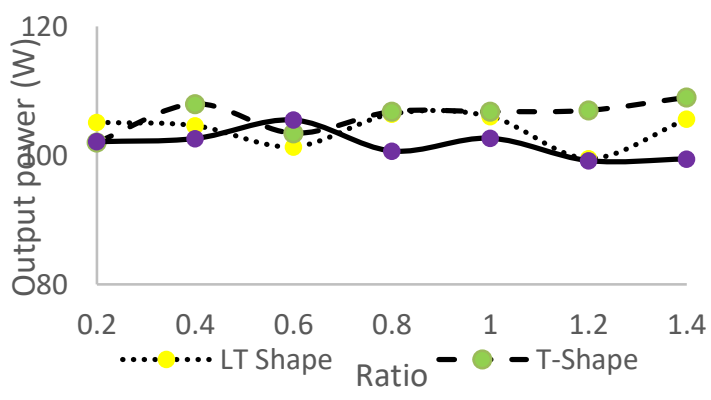

(a)

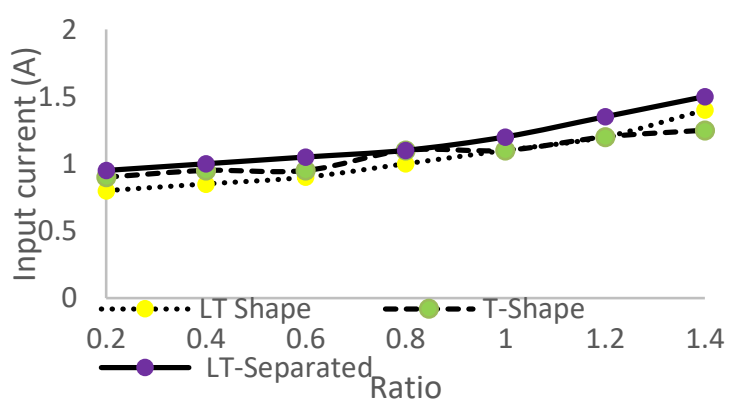

(b)

Figure 3. (a) rated output power and (b) input current 


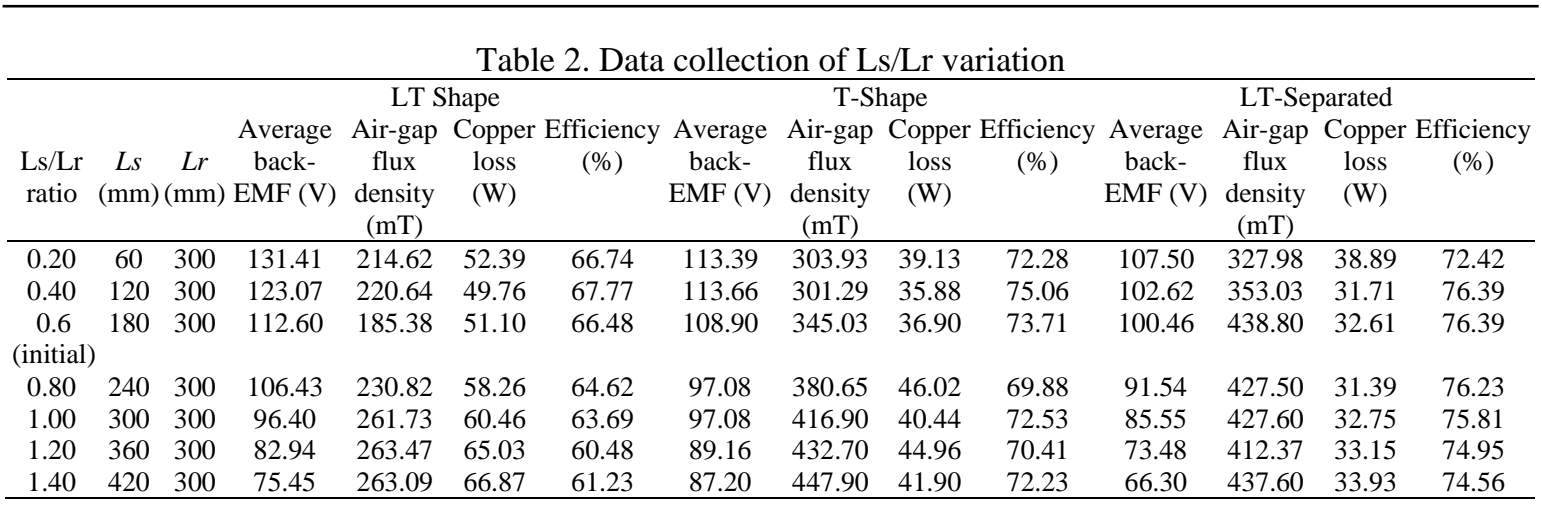

\subsection{Influence of pitch ratio, $\tau_{m r} / \tau_{p}$}

The pitch ratio variation analysis was conducted by varying the length of, $\tau_{m r}$ while the length of $\tau_{p}$ was kept constant. $\tau_{m r} / \tau_{p}$ was carried out to study the influences of rare earth permanent magnetism potential for each pole pair. This variation provides an optimally balanced ratio of magnet pole configuration and enhances the shape of resultant electromagnetic characteristics waveforms. The data collected of the average air-gap flux density, back-EMF, losses, and the efficiency of the influences of $\tau_{m r} / \tau_{p}$ variation are tabulated in Table 3.

Table 3. Data collection of Tmr/Tp variations

\begin{tabular}{|c|c|c|c|c|c|c|c|c|c|c|c|c|c|c|}
\hline \multirow[b]{2}{*}{$\mathrm{Tmr} / \mathrm{Tp}$} & \multirow[b]{2}{*}{$\begin{array}{c}\operatorname{Tmr}(\mathrm{m} \\
\mathrm{m})\end{array}$} & \multirow[b]{2}{*}{$\begin{array}{c}\mathrm{Tp} \\
(\mathrm{mm})\end{array}$} & \multicolumn{4}{|c|}{ LT Shape } & \multicolumn{4}{|c|}{ T-Shape } & \multicolumn{4}{|c|}{ LT-Separated } \\
\hline & & & $\begin{array}{c}\text { Average } \\
\text { back- } \\
\text { EMF (V) }\end{array}$ & $\begin{array}{c}\text { Air-gap } \\
\text { flux } \\
\text { density } \\
\text { (mT) }\end{array}$ & $\begin{array}{c}\text { Copper } \\
\text { loss } \\
\text { (W) }\end{array}$ & $\begin{array}{l}\text { Efficiency } \\
\quad(\%)\end{array}$ & $\begin{array}{l}\text { Average } \\
\text { back- } \\
\text { EMF (V) }\end{array}$ & $\begin{array}{l}\text { Air-gap } \\
\text { flux } \\
\text { density } \\
\text { (mT) }\end{array}$ & $\begin{array}{c}\text { Copper } \\
\text { loss } \\
\text { (W) }\end{array}$ & $\begin{array}{c}\text { Efficiency } \\
(\%)\end{array}$ & $\begin{array}{l}\text { Average } \\
\text { back- } \\
\text { EMF (V) }\end{array}$ & $\begin{array}{c}\text { Air-gap } \\
\text { flux } \\
\text { density } \\
\text { (mT) }\end{array}$ & $\begin{array}{c}\text { Copper } \\
\text { loss } \\
\text { (W) }\end{array}$ & $\begin{array}{l}\text { Efficiency } \\
(\%)\end{array}$ \\
\hline 0.25 & 7.5 & 30 & 102.80 & 276.88 & 35.45 & 75.28 & 116.36 & 352.91 & 30.95 & 77.19 & 105.08 & 282.59 & 24.90 & 80.04 \\
\hline $\begin{array}{c}0.5 \\
\text { (initial) }\end{array}$ & 15 & 30 & 102.45 & 457.83 & 37.80 & 74.00 & 115.27 & 303.95 & 36.38 & 75.06 & 102.62 & 353.03 & 31.71 & 76.39 \\
\hline 0.75 & 22.5 & 30 & 114.93 & 349.60 & 13.82 & 88.21 & 108.81 & 281.74 & 36.71 & 73.79 & 118.21 & 258.11 & 21.22 & 83.37 \\
\hline 1 & 30 & 30 & 114.32 & 213.79 & 11.46 & 89.98 & 107.31 & 258.35 & 37.44 & 73.14 & 115.52 & 159.72 & 13.20 & 88.73 \\
\hline
\end{tabular}

All the designs showed the of $\tau_{m r} / \tau_{p}$ ratio variation with different average air-gap flux density values in which flux density magnitude for each cycle was not constant. Thus, significant to the different volumes of magnets per pole and resulted in the amount of magnetic flux attraction that was not constant. The proposed $\mathrm{T}$-shape design demonstrated higher air-gap flux density at the ratio of 0.25 . Meanwhile, the LT shape and LT-separated designs revealed a higher average air-gap flux density at the ratio of 0.50 because both LT shape has redundant axial and radial magnetization at the edge flux at the same ratio. The back-EMF values of this variation reached the induced voltage generated to have pico-scale output power. The average value of back-EMF was acceptable and still higher than the leading Ls/Lr parameter for the pico-scale power generation. The variation of of $\tau$ mr $/ \tau \_$pfrom the initial design value for LT-shape and LT separated gave rise to the amount of copper loss, found at a ratio of 1.0, which possibly due to the increment of magnet volume in all the proposed designs thus, it improved the magnetic flux density and the back-EMF. In contrast to the copper loss of the T-shape design, the larger magnet volume caused a higher copper loss. In the overview, the designs were showing highefficiency values of above $70 \%$ for the pitch ratio. As the proposed designs were created with minimum copper losses, the resulting high-efficiency values of $89.9 \%$ and $88.7 \%$, respectively, were reported at the ratio of 1.0. The proposed T-shape design was having a higher efficiency value of $77.2 \%$ at a ratio of 0.25 . Therefore, the best efficiency for the designs in the varied $\tau \_\mathrm{mr} / \tau$ _pratio was further optimized for the split ratio.

\subsection{Influence of split ratio, $\mathrm{Rm} / \mathrm{Re}$}

Based on the previous analyses reported regarding the $\tau_{m r} / \tau_{p}$ variation, the best efficiency with the minimum power loss was selected for further improve design parameter. The split ratio is defined as the optimal balance between the magnetic and electrical loading. The external diameter of the stator core is maintained while varying the magnet's outer radius. The average air-gap flux density waveform of $R_{m} / R_{e}$ variation is as tabulated in Table 4. There were different average airgap flux density values observed between all the designs variations of $R_{m} / R_{e}$ ratio due to the higher volume of radius magnet per pole and higher magnetic flux attractions. Therefore, it was observed that the air-gap flux density value increases due to $R_{m} / R_{e}$ ratio 
increases, as supported by the findings of [23]-[25]. The findings demonstrated that the back-EMF reached the induced voltage produced to have the output power at the pico-scale. Thus, more input currents are being injected into the designs. The decreasing copper loss affected the higher efficiency performances of the designs and leads to the decreasing of the magnetic flux. So, this can contribute to the smaller PMLG designs into a portable form. From all the designs, the proposed LT shape and LT-separated shape designs were showing the higher efficiency of $93.36 \%$ and $94.09 \%$, respectively, while T-shape, $87.28 \%$. The efficiency performance of the designs was extracted from the leading parameter which is the last variation of the split ratio. As summarized in this refined design parameter process, all the designs can generate $\pm 100 \mathrm{~W}$ output power despite the pico-scale power output. The highest efficiency obtained by the LT-separated and LT shape design was shown to be above $90 \%$. This is because of the magnet shape and the double magnetization caused by the axial and radial arrays.

Table 4. Data collection of $\mathrm{Rm} / \mathrm{Re}$ variation

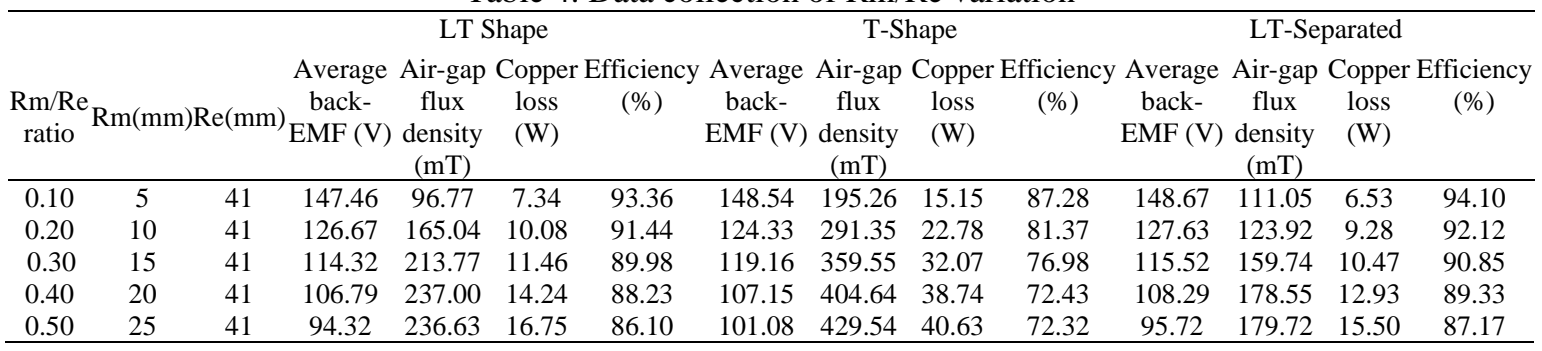

\section{CONCLUSION}

Three pico-scale proposed PMLG designs for WEC in Malaysia has been analyzed in term of leading parameters variation against the same rated output of $100 \mathrm{~W}$. All proposed designs are capable to produce $100 \mathrm{~W}$ as desired. Moreover, all design also yields satisfactory efficiency above the $90 \%$. Even though all design has the same magnetization of Halbach array and same volume but in different shape of the permanent magnet, however, affect to the magnetization in increasing the resistance of the winding. Therefore, the final designs have been selected for further validation using analytical computation which are LT separated designs that have higher efficiency at the least ratio of $\mathrm{Rm} / \mathrm{Re}$ variations.

\section{ACKNOWLEDGEMENTS}

The authors acknowledge the support from Universiti Teknologi PETRONAS for the award by graduate assistants and research facilities.

\section{REFERENCES}

[1] P. A. Østergaard, N. Duic, Y. Noorollahi, H. Mikulcic, and S. Kalogirou, "Sustainable Development Using Renewable Energy Technology," Renewable Energy, vol. 146, pp. 2430-2437, February 2020, doi: 10.1016/j.renene.2019.08.094.

[2] A. M. Omer, "Energy use and environmental impacts: A general review," Journal Renewable Sustainable Energy, vol. 1, no. 5, p. 053101, 2009, doi: 10.1063/1.3220701.

[3] R. Vermaak and M. J. Kamper, "Design Aspects of a Novel Topology Air-Cored Permanent Magnet Linear Generator for Direct Drive Wave Energy Converters," in IEEE Transactions on Industrial Electronics, vol. 59, no. 5, pp. 2104-2115, May 2012, doi: 10.1109/TIE.2011.2162215.

[4] S. C. Loon and J. Koto, "Wave Energy for Electricity Generation in Malaysia-Merang Shore, Terengganu," International Journal of Energy and Environment, vol. 304, pp. 8-18, 2016.

[5] A. Mirzaei, F. Tangang, and L. Juneng, "Wave energy potential along the east coast of Peninsular Malaysia," Energy, vol. 68, pp. 722-734, April 2014, doi: 10.1016/j.energy.2014.02.005.

[6] N. S. Abd Ghani, I. Taib, and N. M. Nor, "Designing of a generator for wave energy conversion for outdoor activities," International Journal of Power Electronics and Drive Systems (IJPEDS), vol. 11, no. 3, pp. 1415-1422, September 2020, doi: 10.11591/ijpeds.v11.i3.pp1415-1422.

[7] Y. Nagata and T. Konno, "Wave activated power generation device and wave activated power generation plant," 2009.

[8] A. H. Memon, T. bin Ibrahim, and N. Perumal, "Portable and pico-scale linear generator for wave energy conversion," 2014 5th International Conference on Intelligent and Advanced Systems (ICIAS), 2014, pp. 1-4, doi: 10.1109/ICIAS.2014.6869479.

[9] H. Asiful and H. S. Che, "Design and Simulation of Axial Flux Permanent Magnet Generator for Residential Pico-Hydro Power Generation," 2018 International Conference on Intelligent and Advanced System (ICIAS), 2018, pp. 1-5, doi: 10.1109/ICIAS.2018.8540629.

[10] İ. Ö. Erselcan and A. Kukner, "A Review of Power Take-Off Systems Employed in Wave Energy Converters," Journal Navel. Science. Engineering, vol. 10, no. 1, pp. 32-44, 2014.

[11] B. Rezaeealam, "Losses Computation in Reciprocating Tubular Permanent Magnet Generator with SMC Core," International Journal of Power Electronics and Drive Systems (IJPEDS), vol. 9, no. 4, pp. 1545-1551, December 2018, doi: 10.11591/ijpeds.v9.i4.pp1545-1551.

[12] H. Chen, S. Zhao, H. Wang, and R. Nie, "A Novel Single-Phase Tubular Permanent Magnet Linear Generator," in IEEE 
Transactions on Applied Superconductivity, vol. 30, no. 4, pp. 1-5, June 2020, doi: 10.1109/TASC.2020.2976948.

[13] M. Richter, M. E. Magana, O. Sawodny, and T. K. A. Brekken, "Nonlinear Model Predictive Control of a Point Absorber Wave Energy Converter," in IEEE Transactions on Sustainable Energy, vol. 4, no. 1, pp. 118-126, Jan. 2013, doi: 10.1109/TSTE.2012.2202929

[14] G. Bacelli, J. V. Ringwood, and J.-C. Gilloteaux, "A control system for a self-reacting point absorber wave energy converter subject to constraints," IFAC Proceedings Volumes, vol. 44, no. 1, pp. 11387-11392, January 2011, doi: 10.3182/20110828-6-IT1002.03694.

[15] I. Petrov and J. Pyrhonen, "Performance of Low-Cost Permanent Magnet Material in PM Synchronous Machines," in IEEE Transactions on Industrial Electronics, vol. 60, no. 6, pp. 2131-2138, June 2013, doi: 10.1109/TIE.2012.2191757.

[16] N. Shahabudin, I. Taib, and N. A. M. Zamri, "Portable pico linear generator design with different magnet shapes for wave energy conversion system," International Journal of Power Electronics and Drive Systems (IJPEDS), vol. 8, no. 1, pp. 360-366, March 2017, doi: 10.11591/ijpeds.v8i1.pp360-366.

[17] K. J. Meessen, B. L. J. Gysen, J. J. H. Paulides, and E. A. Lomonova, "Halbach Permanent Magnet Shape Selection for Slotless Tubular Actuators," in IEEE Transactions on Magnetics, vol. 44, no. 11, pp. 4305-4308, Nov. 2008, doi: 10.1109/TMAG.2008.2001536.

[18] A. Kaddouri and H. Le-Huy, "Analysis and design of a slotless NdFeB permanent-magnet synchronous motor for direct drive," Conference Record of the 1992 IEEE Industry Applications Society Annual Meeting, vol. 1, pp. 271-278, 1992, doi: 10.1109/IAS.1992.244284.

[19] J. Ma and Z. Q. Zhu, "Optimal split ratio in small high speed PM machines considering both stator and rotor loss limitations," in CES Transactions on Electrical Machines and Systems, vol. 3, no. 1, pp. 3-11, March 2019, doi: 10.30941/CESTEMS.2019.00002.

[20] T. Balachandran, S. Srimmana, A. Anderson, X. Yi, N. Renner, and K. S. Haran, "Assembly and Qualification of a Slotless Stator Assembly for a MW-Class Permanent Magnet Synchronous Machine," 2020 AIAA/IEEE Electric Aircraft Technologies Symposium (EATS), 2020, pp. 1-10

[21] S. Vaez-Zadeh and A. H. Isfahani, "Multiobjective design optimization of air-core linear permanent-magnet synchronous motors for improved thrust and low magnet consumption," in IEEE Transactions on Magnetics, vol. 42, no. 3, pp. 446-452, March 2006, doi: 10.1109/TMAG.2005.863084

[22] J. Wang and D. Howe, "Tubular modular permanent-magnet machines equipped with quasi-Halbach magnetized magnets-part I: magnetic field distribution, EMF, and thrust force," in IEEE Transactions on Magnetics, vol. 41, no. 9, pp. 2470-2478, Sept. 2005, doi: 10.1109/TMAG.2005.854328.

[23] N. Feng, H. Yu, M. Zhao, P. Zhang, and D. Hou, "Magnetic Field-Modulated Linear Permanent-Magnet Generator for Direct-Drive Wave Energy Conversion," IET Electrical Power Application, vol. 14, no. 5, pp. 742-750, Feb. 2020, doi: 10.1049/ietepa.2019.0483.

[24] X. Zhou, O. Abdelkhalik, and W. Weaver, "Power take-off and energy storage system static modeling and sizing for direct drive wave energy converter to support ocean sensing applications," Journal of. Marine. Science and Engineering, vol. 8, no. 7, p. 513, 2020, doi: 10.3390/jmse8070513.

[25] A. S. Saari and D. Ishak, "Design and fault-tolerant analysis of five-phase permanent magnet synchronous motor," Indonesian Journal of Electrical Engineering and Computer Science, vol. 16, no. 3, pp. 1115-1125, December 2019, doi: 10.11591/ijeecs.v16.i3.pp1115-1125.

[26] T. Nireekshana and V. R. Babu, "Design and fabrication of linear induction motor for traction application," International Journal of Electrical and Electronics Engineering (IJEEE), vol. 6, no. 6, pp. 1-18, 2017.

\section{BIOGRAPHIES OF AUTHORS}
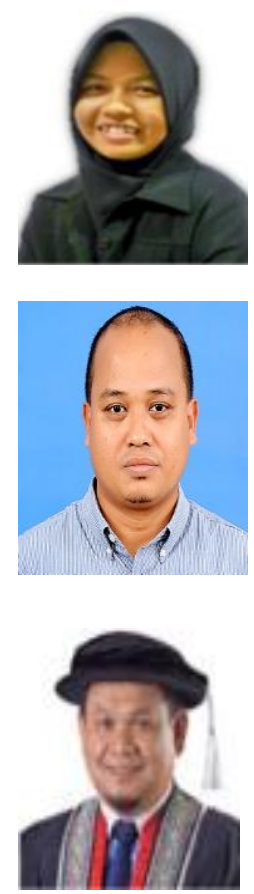

Noor Syazana Abd Ghani (D) SC P was born in Perlis, Malaysia, in 1996. She obtained her Bachelor's degree in Electrical and Electronic Engineering from Universiti Teknologi PETRONAS in 2019 and M.Sc degree with the Department of Electrical and Electronic Engineering, Universiti Teknologi PETRONAS, Malaysia in 2022. Her current research interest includes linear electrical machine design, renewable energy (wave) and power electronics. Email: noorsyazanaabdghani@gmail.com.

Taib Ibrahim (iD) 8d SC P obtained his Bachelor's degree in Electrical and Electronic Engineering from Coventry University, UK, in 1996 and M.Sc in Electrical Power Engineering from University of Strathclyde, UK, in 2001. Ph.D. in Electrical Machine Design from University of Sheffield, UK, in 2009. He has published more than 20 journal papers on various aspects of electrical machine design and energy. At present, he is working as Associate Professor in Universiti Teknologi PETRONAS. His current research interest includes linear and rotary electrical machine design, renewable energy (hydro and wave), power electronic converter, and electrical power protection system. Email: taibib@utp.edu.my.

Nursyarizal Mohd Nor (iD) 8 SC P obtained his Bachelor's degree in Electrical and Electronic Engineering from Universiti Teknologi Mara in 1998 and MSc in Electrical power Engineering from UMIST University, UK, in 2001. Ph.D. in Electrical \& Electronics Engineering from Universiti Teknologi PETRONAS, Malaysia, in 2009. He has published more than 20 journal papers on various aspects of electrical machine design and energy. At present, he is working as Associate Professor at Universiti Teknologi PETRONAS. His current research interest includes power electronics, operation and control, electrical machine and power systems. Email: nursyarizal_mnor@utp.edu.my. 